\title{
Vascular Amyloid in the Aging Central Nervous System Clinico-Pathological Study and Literature Review
}

\author{
JOSEPH BRUNI, JUAN M. BILBAO, AND KENNETH P. H. PRITZKER
}

SUMMARY: The clinico-pathological features of five patients with vascular amyloid restricted to the central nervous system are presented.

In three normotensive patients, intracerebral hemorrhage was the dramatic manifestation of amyloid angiopathy. In two other cases, one of amyloid in an arteriovenous malformation, the other of amyloid following therapeatic radiation, amyloid deposition was asymptomatic.

RESUMÉ: Nous présentons l'aspect clinico-pathologique de cinq patients dont l'amyloïdose vasculaire était limitée au système nerveux central.

Chez trois patients normotensifs, une hémorrhagie intracérébrale fut la manifestation dramatique de l'angiopathie amyloidienne. Chez deux autres cas, l'un présentant une accumulation d'amyloïde dans une malformation artério-veineuse, l'autre ayant une amylö̈dose à la suite d'irradiation thérapeutique, le dépôt amyloïde fut asymptomatique.
Clinically, amyloid angiopathy.must be considered in the different diagnosis of intracerebral hemorrhage, independent of the presence of dementia. Pathologically, a factor common to the syndrome of cerebrovascular amyloid appears to be locally increased vascular permeability resulting from a variety of previous tissue injuries.

Du point de vue clinique il faut considérer l'angiopathie amyloidienne dans le diagnostic différentiel d'une hémorrhagie cérébrale, qu'il y ait ou non une démence. Du point de vue pathologique il semble qu'un des facteurs communs dans le syndrome de l'amyloïdose cérébro-vasculaire soit l'augmentation locale de la perméabilité vasculaire résultant d'une variété de lésions tissulaires préalables.
From the Departments of Pathology, St. Michael's Hospital, Mount Sinai Hospital and University of Toronto, Toronto, Canada.

Reprint requests to: Dr. Kenneth P. H. Pritzker, Division of Pathology, Mount Sinai Hospital, 600 University Avenue, Toronto, Ontario, Canada M5G IXS.
Amyloid deposition restricted to central nervous tissue has been reported with a variety of neurological conditions including dementia (Mandybur, 1975), stroke (Torack, 1975) and, recently, a progressive demyelinating syndrome (Heffner et al., 1976). Within the central nervous system, amyloid may be found locally in the cortical neuropil (senile plaques) (Divry, 1927), or in the vicinity of blood vessel walls (Van Bogaert, 1970). Although vascular amyloid has been associated with Alzheimer's disease and cerebral hemorrhage, amyloid within blood vessels may be found without symptoms as an isolated incidental finding at autopsy or in conjunction with post radiation brain necrosis or in arteriovenous malformations.

Despite numerous sporadic case reports and a few specialized review articles, the clinical manifestations of cerebrovascular amyloid are not widely appreciated. Indeed, amyloid is not mentioned as a cause of cerebral hemorrhage in the recent text on cerebral blood vessel pathology by Stehbens (1972). This report illustrates our experience with five cases of vascular amyloidosis restricted to the central nervous system. This includes three cases of spontaneous intracerebral hemorrhage, one case of post-radiation amyloid and one case of amyloid associated with a vascular malformation. In all cases, amyloid was specifically demonstrated by apple green birefringence when Congo-red stained sections were viewed with a polarizing microscope (Divry and Florkin, 1927, Ladewig 1945) and by yellowish fluorescence on thioflavine $T$ 
stained sections (Vassar and Culling, 1959).

\section{CASE REPORTS}

\section{Case 1}

This 82 year old man was admitted to St. Michael's Hospital, unconscious. His previous health was entirely unremarkable. Physical examination revealed normal blood pressure and an irregular pulse. There was no neck rigidity; no cranial bruits were heard and the cranial nerves were intact. A right hemiparesis, bilateral Babinski responses and sensory response to painful stimuli only were demonstrated. Electrocardiogram revealed an anteroseptal infarction with frequent atrial premature beats. Skull $x$-rays were normal. Brain scan showed an area of increased radionucleotide uptake on the left side suggesting a subdural hematoma. The clinical diagnosis was left middle cerebral artery thrombosis. Two and a half months after admission, the patient died from pneumonia, renal failure and pulmonary embolism.

At autopsy, a thin organizing subdural hematoma was found over the left cerebral convexity. There was moderate cortical atrophy of both the frontal and temporal lobes. An hemorrhagic infarct in the left second frontal gyrus and several small cavitating infarcts in the right frontal cortex were found. Histologically, amyloid infiltrates were demonstrated in the meningeal, the cortical penetrating and intracerebral blood vessels. Amyloid was observed both in vessels within the infarcted areas and in areas without other demonstrable pathology. Occasional senile plaques throughout the cortex were observed but no neurofibrillary tangles were found. Amyloid was not demonstrated in the heart or other organs.

\section{Case 2}

This 75 year old woman was admitted to St. Michael's Hospital with a diagnosis of subarachnoid hemorrhage. Two years previously she was hospitalized because of the sudden onset of "confusion" and headache. At that time examination revealed a normal blood pressure, disorientation, fluent aphasia, and finger agnosia. The patient made an almost complete recovery spontaneously. She was well until three days prior to the present admission when she suddenly became confused and disoriented. On admission she had a blood pressure of $140 / 60$. There was mild neck rigidity. No focal neurologic signs could be elicited. Bilateral cerebral angiograms revealed a left frontal mass interpreted as a neoplasm. A left frontal craniotomy was performed and a large intracerebral blood clot was removed. No tumor was found. In the surgical biopsy specimen, the wall of the meningeal and cortical penetrating vessels showed abundant amyloid infiltrates. As well, numerous senile plaques were demonstrated but no neurofibrillary tangles were found. Postoperatively, the patient developed inappropriate antidiuretic hormone secretion syndrome, her condition deteriorated and she died. A postmortem examination was not obtained.

\section{Case 3}

This 76 year old woman with a three year history of motor neuron disease was admitted to Baycrest Hospital because she suddenly was unable to be fed without choking on her saliva. Neurological examination revealed that the gag reflex was present but she was unable to swallow. Fasciculations of the chin muscles and muscles in the extremities were noted. There was marked muscular atrophy of the muscles of the upper and lower extremities. Shortly after admission she died.

At autopsy, extensive neuronal loss in the anterior horns throughout the spinal cord and the hypoglossal nuclei were seen. Recent hemorrhage was found in the left basal ganglia communicating with the lateral ventricle. Fresh blood was present throughout the ventricular system. No herniation was seen. Microscopically extensive amyloid deposits were found in the cortical blood vessels (Fig. 1). Within the hemorrhage, a vessel with a Charcot-Bouchard aneurysm was seen (Fig. 2). With polarized light, it was observed that the aneurysm was a false aneurysm, and that the wall of the aneurysm was composed of new collagen, whereas the wall of the blood vessel was composed of amyloid (Fig. 3). No amyloid deposits were found elsewhere in the body.

\section{Case 4}

This 73 year old man was last admitted to St. Michael's Hospital in April, 1976 with increasing dyspnea, confusion, weakness and ataxia. A diagnosis of poorly differentiated squamous cell carcinoma of the lung was made in June, 1975. Subsequently, he received 3000 rads of radiotherapy to the anterior and posterior right lower chest. Because of an area of increased radionucleotide uptake over the right occipital area, the patient received 2000 rads cobalt 60 radiotherapy to the right and left lateral aspects of the skull. In January, 1976, the patient presented with symptoms of confusion. A metastatic cerebral lesion was confirmed with a brain scan. At this time the patient received 600 rads cobalt 60 radiotherapy to the right and left lateral brain areas. Simultaneously, he was treated with steroids. He developed bronchopneumonia and died in May, 1976.

At autopsy, examination of the brain revealed metastatic poorly differentiated squamous cell carcinoma in the right parietal area with local carcinomatous meningeal infiltration. In both parietal lobes, the meningeal and cortical penetrating vessels were infiltrated by amyloid. In the left parietal lobe there were several cavitating infarcts with vessels containing amyloid leading to the infarcted area. Amyloid deposition was not demonstrated elsewhere in the neuraxis or in the general autopsy. In the left parietal lobe there were areas of hypertrophic astrocytes indicative of radiation effect.

\section{Case 5}

This 70 year old man was admitted to Mount Sinai Hospital with anorexia, fatigue and weight loss as the presenting manifestations of acute myeloblastic leukemia. Despite therapy with Cytosine 
arabinoside and Danunorubimycin his condition deteriorated, and he died within a month of admission. Neurological examination on admission revealed decreased sensation to pin-prick and touch in the legs to midcalf distally and a slight decrease in vibration sense in the toes bilaterally. Position sense was normal. Plantar responses were normal.

At autopsy, widespread leukemic infiltrates and candida sepsis were shown to be the immediate cause of death. As an incidental finding a granular area of increased vascularity was observed in the pons and medulla oblongata. On section, a diffuse vascular malformation was present in the central portion of the brain stem. This consisted of numerous dilated blood vessels separated by degenerated neuropil. The vascular malformation was present in the pyramids, the central portion of the medulla and in the periventricular areas. The blood vessels had thick walls containing homogeneous eosinophilic material both within the lumina and within the walls (Fig. 4). Paler staining homogeneous eosinophilic material was seen in nodules within the neuropil outside the blood vessels. The special stains demonstrated that most of the amyloid was present within the vessels of the malformation (Fig. 5.). Most of the homogeneous eosinophilic substance within the blood vessels was shown to be fibrin with Martius scarlet blue and Weigert stain. There was no amyloid deposition elsewhere in the brain or in other organs.

\section{DISCUSSION \\ Amyloid Angiopathy and " Intracerebral Hemorrhage}

Until recently, amyloid angiopathy was thought to be associated either with systemic amyloidosis or with senile plaques and presenile dementia. However, Neumann (1960), Lampert (1969), and Torack (1975) have demonstrated that vascular amyloid may occur without neurofibrillary tangles or dementia. Furthermore, the observation that vessels containing amyloid can rupture causing fatal intracerebral hemorrhage in normotensive patients is evidence that vessel walls containing amyloid may be weaker than normal.

The three patients with intracerebral hemorrhage described in this report resemble closely the cases of Torack (1975) in age and mode of presentation. It is important to emphasize that none of our patients had a history of hypertension. Although increased numbers of senile plaques were present compared to other persons of similar age, no neurofibrillary degeneration could be demonstrated and there was no clinical evidence of dementia. In Case 3, it was shown that the wall of the Charcot-Bouchard aneurysm consisted of collagen, not amyloid. This indicated that, contrary to other sites such as the skin (Hashimoto and Brownstein 1972), amyloid was not produced during the repair process.

Pathologically, amyloid deposits were found in all cases to affect many cerebral blood vessels other than the vessels directly involved in the hemorrhage. However, amyloid was not seen in the blood vessels or interstitium of any other organs. Therefore, cerebrovascular amyloid appears to represent a localized disorder distinct from Alzheimer's disease or generalized amyloidosis.

Hereditary cerebral hemorrhage with amyloidosis has also been described (Arnason, 1935; Corsellis and Brierley, 1954; and Gudmundsson, et al., 1972). Gudmundsson, et al. (1972) concluded that the condition was a hereditary illness with dominant inheritance and with two exceptions, complete penetrance. The patients were considerably younger than is usual with intracerebral hemorrhage and younger than the patients of Torack (1975) or this series. All the patients presented with sudden catastrophic central nervous system damage. None of the patients had hypertension. Histological examination of five autopsy cases revealed amyloid deposits in cerebral arteries of all patients.
Vascular Amyloid Secondary

to Radiation Therapy

There is controversy as to whether the eosinophilic infiltrate in vessel walls following radiotherapy is amyloid. As Lampert (1968) points out, these deposits may stain with Congo-red, but do not usually have the other histochemical properties of amyloid. Most of this material is insudated fibrin resulting from the increased vascular permeability from radiation injury.

The case presented here showed amyloid vascular changes only in areas of the brain within the radia. tion field. Amyloid was specifically demonstrated both by apple green birefringence with Congo-red stain and by yellow thioflavine $T$ fluorescence.

Amyloid was shown in vessels both in areas of necrosis and in areas in which necrosis was absent. As the interval between the time of the first radiation treatment and death was ten months in this case, the amyloid degeneration occurred over a relatively short period. There was no evidence of a more generalized cerebral blood vessel involvement. Senile plaques were not seen. The total dose of radiation delivered, 2600 rads, was not excessive either in terms of acceptable total dosage or time interval over which it was delivered.

Fischer and Holdfelder (1930) were the first to report amyloid vascular changes secondary to radiation. Other cases of vascular amyloid degeneration following radiation have been reported by Lowenberg-Scharenberg and Bassett (1950), and Foltz et al. (1953). Mandybur and Gore (1969) reported two cases of amyloid in late postradiation necrosis secondary to radiation treatment of two extracranial basal cell carcinomas of the scalp. The symptom-free intervals were three years and four years after the last radiation treatments, respectively. Amyloid deposition in the cerebral vessels occurred only in areas of necrosis. Mandybur and Gore (1969) speculated that necrosis was a prerequisite for amyloid deposition, an observation contrary to the findings in our case. 


\section{VASCULAR AMYLOID IN THE \\ AGING CENTRAL NERVOUS SYSTEM}

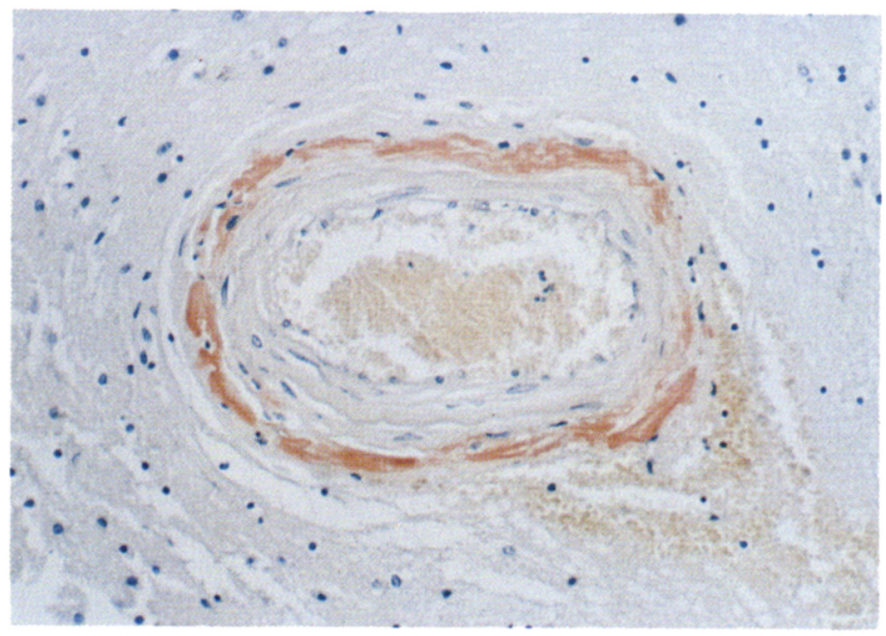

Figure 1

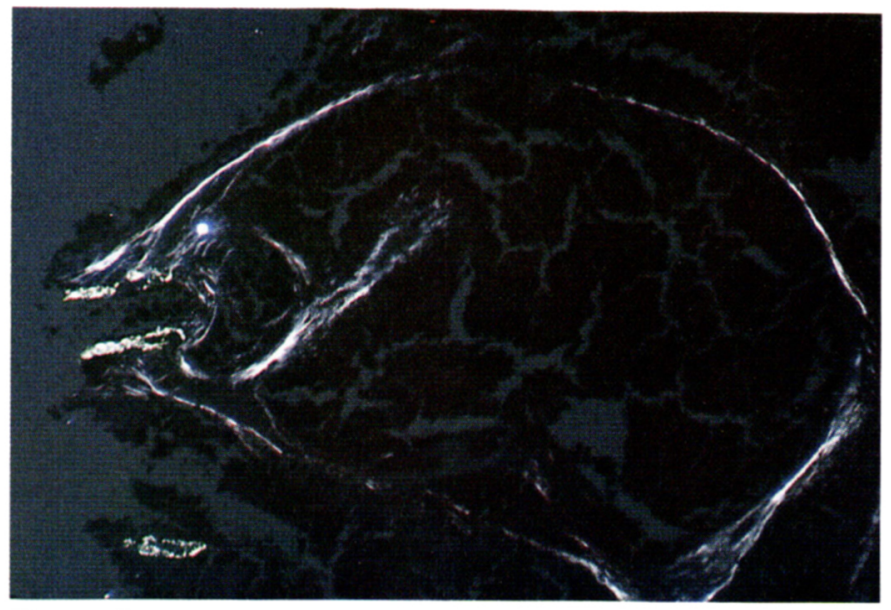

Figure 3

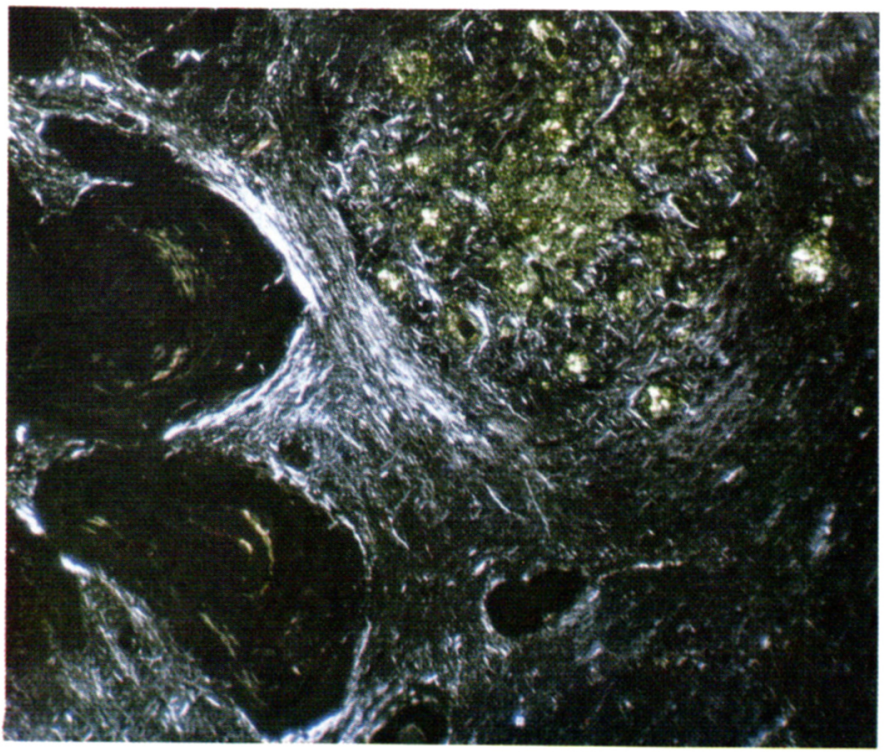

Figure 5 
Amyloid in Vascular Malformations Neumann (1960), Peterson and Schulz (1961) and McCormick (1966) each reported a case of amyloid within an arteriovascular malformation. Neumann (1960) described a patient who died from an intracerebral hemorrhage arising from one of several small vascular malformations. Amyloid was demonstrated by Congo-red staining of the small malformations in other vessels within the malformation. Senile plaques containing amyloid were also present. There was no evidence of generalized amyloidosis.

Peterson and Schulz (1961) reported a diabetic patient with amyloid deposition in a cerebrovascular malformation in the absence of amyloid in other cerebral vessels or other organs. The amyloid was identified by Congo-red staining and $\mathrm{Thi}-$ oflavine $\mathrm{T}$ fluorescence. This malformation, located in the white matter of the right frontal lobe, was asymptomatic. McCormick (1966) in his review of 70 vascular malformations demonstrated amyloid in the vessel walls of one case. In our case, the bulk of the amyloid was found in nodules within the neuropil adjacent to the blood vessels. Although some amyloid was shown within the blood vessel walls, most of the homogeneous eosinophilic substance present was fibrin. Senile plaques were not found in our case. There was no evidence of generalized amyloidosis or amyloid depositon in other blood vessels.

\section{Origin of Cerebrovascular Amyloid}

In the absence of amyloid deposits in other organs, cerebrovascular amyloid must be related to a local process within the cerebral blood vessel walls. In cases following radiation, increased permeability of the vessel walls to proteins has been shown. It is reasonable to postulate that a similar increase in permeability may be present in some arteriovenous malformations and in portions of the brain which have undergone previous inflammatory e.g. luetic or degenerative changes. e.g. Alzheimer's disease, Down's syndrome.

Thus, we are postulating that amyloid angiopathy may be secondary to vascular changes in a previously injured area and not a primary cause of dementia or demyelinating syndrome. Unfortunately, the nature of this study does not provide

Figure I-Intracerebral blood vessel showing brown amorphous amyloid deposition within the vessel wall.

Congo-red. Magnification x 16 .

Figure 2-Ruptured vessel with a Charcot-Bouchard aneurysm in the midst of an intracerebral hemorrhage.

Hematoxylin and Eosin. Magnification x 25 .

Figure 3-Same field as Figure 2. At the left, the wall of the vessel leading into the aneurysm shows apple green birefringence characteristic of amyloid degeneration. Amyloid is also seen in the non-involved vessel below. The aneurysm wall itself is composed of collagen fibers which are coarser and have a white birefringence.

Congo-red. Polarized light. Magnification x 25.

Figure 4-Arteriovenous malformation of the brain stem. Dark staining amorphous eosinophilic material is observed in the blood vessel walls and lumena. In the adjacent neuropil, spherical masses of amorphous pale staining eosinophilic material are seen.

Hematoxylin and Eosin. Magnification x 16.

Figure 5-Same field as Figure 4. The apple green birefringence identifies amyloid as the major component of the amorphous material within the neuropil. Only small amounts of amyloid are present within the blood vessel walls. (The remainder of this material stained strongly for fibrin). The white birefringent fibers in the brain parenchyma and blood vessel walls are collagen fibers.

Congo-red. Polarized light. Magnification x 16. information on the relative merits of possible amyloidogenic mechanisms, such as the role of circulating precursors, the contribution of immunoglobulin fragments or the role of reactions within the neuropil.

From this study, we conclude that central nervous system amyloid angiopathy can occur without dementia, and that amyloid angiopathy is an important cause of intracerebral hemorrhage in the normotensive elderly population. It is speculated that the factor common to various forms of cerebrovascular amyloid deposition is a local increase in vascular permeability resulting from previous tissue injury.

\section{ACKNOWLEDGEMENT}

The authors wish to thank Ms. Lorraine Green for preparation of the manuscript.

\section{REFERENCES}

AFRA, D., MULLER, W. and WILCKE. $O$. (1961). Die Fruhwirking ionisierender Strahlen $\left(\mathrm{Co}^{60}\right)$ auf die menschliche Gehirn. Strahlentherapie 116, 231-241.

ARNASON. A. (1935). Apoplexien Ihre Verebung. Acta Psychiatrica et Neurologica Supplement VII.

COHEN, A. S. (1967). Amyloidosis. New England Journal of Medicine, 277, 522-530. 574, 583, 628-638.

CORSELLIS, J. A. N. and BRIERLEY. J. B. (1954). An unusual type of presenile dementia. Brain. 77. 571.586.

DIVRY, P. (1927). Etude histochemique des plaques seniles. Journal Belge de Neurologie. 27, 643-657.

DIVRY, P. and FLORKIN, N. (1927). Sur les propétés optiques de l'amyloide. C. R. Soc. Biol. (Paris). 97, 1808-1810.

DIVRY, P. (1952). La pathochimie generale et cellulaire des processus seniles et preseniles. Proceedings of the First International Congress on Neuropathology, Rome. 2, 313-345. Rosenberg and Sellier, Turin.

FISCHER, A. W. and HOLDFELDER, $H$. (1930). Lokales amyloid in Gehirn. Eine Spatfolge Von Rontgenhestrahlungen. Deutsche Zeitschrift fur Chirurgie, 227, 475-483.

FOLTZ, E. E., HOLYOKE, G. B. and HEYL, H. L. (1953). Brain necrosis following $x$-ray therapy. Journal of Neurosurgery, 10, 423-429.

GUDMUNDSSON, G.. HALLGRIMSSON, J., JONASSON, T. and BJARNASON, O. (1972). Hereditary cerebral hemorrhage with amyloidosis. Brain, 95, 387-404.

HASHIMOTO, K. and BROWNSTEIN. M. H. (1972). Amyloidogenesis in healing 
wound. American Journal of Pathology, 68, $377-380$.

HEFFNER, R. R., JR., PORRO, R. S., OLSON, M. E. and EARLE, K. M. (1976). A demyelinating disorder associated with cerebrovascular amyloid angiopathy. 33, 501-506.

LADEWIG, P. (1945). Double-refringence of the amyloid-congo-red-complex in histological sections. Nature, 156, 81-82.

LAMPERT, P. W. (1968). Amyloid and anyloid-like deposits. In Pathology of the Nervous System. Minckler,J. 1113-1121. McGraw-Hill Book Company, Toronto.

LOWENBERG-SCHARENBERG, $K$. and BASSETT, R. C. (1950): Amyloid degeneration of the human brain following $x$-ray therapy. Journal of Neuropathology and Experimental Neurology, 9, 93-102.

MANDYBUR, T. L. (1975). The incidence of cerebral amyloid angiopathy in Alzheimer's disease. Neurology 25, 120-126.

MANDYBUR, T. I. and GORE, I. (1969). Amyloid in late post irradiation necrosis of brain. Neurology, 19, 983-992.

McCORMICK, W. F. (1966). The pathology of vascular ("arteriovenous") malformations. Journal of Neurosurgery, 24, 807-816.
MOREL, F. and WILDI, E. (1952). General and cellular pathochemistry of senile and presenile alterations of the brain. Proceedings of the First International Congress on Neuropathology, Rome, 2, 347-374. Rosenberg and Sellier, Turin.

NEUMANN, M. A. (1960). Combined amyloid vascular changes and argyrophilic plaques in the central nervous system. Journal of Neuropathology, 19, 370-382.

PETERSON, E. W. and SCHULZ, D. M. (1961). Amyloid in vessels of a vascular malformation in brain. Archives of Pathology, 72, 480-483.

RAVINA, A., PESTEL, $M$. and LAP. RESLE, J. (1959). Necrose Cerebrale apres radiotherapie pour teigne. La Presse Medicale, 67, 1063-1064.

SCHOLZ, W. (1938). Studien Zur pathologie der hirngefasse 1l: Die drusige Entartung der Hirnarterien und Capillaren. Zeitschrift fur die Gesamte Neurologie und Psychiatrie, 162, 694-715.

SCHWARTZ, P. (1972). Amyloidosis of the nervous system in the aged. In Pathology of the Nervous System. Minckler, J. 2812-2849 McGraw-Hill Book Company, Toronto.

STEHBENS, W. E. (1972). Pathology of the cerebral blood vessels. The C. V. Mosby Company, Saint Louis.

TORACK, R. M. (1975). Congophilic angiopathy complicated by surgery and massive hemorrhage. American Journal of Pathology, 81, 349-359.

VAN BOGAERT, L. (1970). Cerebral amyloid angiopathy and Alzheimer's disease. In Ciba Foundation Symposium. Wolstenholme, G. W. E., O'Connor, A. 95-104. J. and A. Churchill, London.

VAN DER HORST, L.. STAM, F. C. and WIGBOLDUS, J. M. (1960). Amyloidosis in senile and pre-senile involutional processes of the central nervous system. Journal of Nervous and Mental Diseases. 130, 578-586.

VASSAR, P. S. and CULLING, C. F. S. (1959). Fluorescent stains with special reference to amyloid in connective tissue. Archives of Pathology, 68, 487-498.

WORSTER-DROUGHT, C.. GREENFIELD, J. G. and McMENEMEY, W. H. (1940). A form of familial presenile dementia with spastic paralysis. Brain, 237-254.

WORSTER-DROUGHT, C., GREENFIELD, J. G. and MCMENEMEY, W. H. (1944). A form of presenile dementia with spastic paralysis. Brain, 67, 38-43. 